\title{
Determinants of Food Security: The Case of Kurmuk District in Benishangul Gumuz Regional State, Western Ethiopia
}

\author{
Seid Mohammed ${ }^{1}$, Abdela Mohammed ${ }^{2}$ \\ ${ }^{1}$ College of Agriculture and Natural Resources, Assosa University, Assosa, Ethiopia \\ ${ }^{2}$ College of Agriculture and Natural Resources, Mizan-Tepi University, Mizan-Tepi, Ethiopia \\ Email address: \\ seidmohh@yahoo.com (S. Mohammed)
}

\section{To cite this article:}

Seid Mohammed, Abdela Mohammed. Determinants of Food Security: The Case of Kurmuk District in Benishangul Gumuz Regional State, Western Ethiopia. International Journal of Natural Resource Ecology and Management. Vol. 6, No. 1, 2021, pp. 16-26.

doi: 10.11648/j.ijnrem.20210601.14

Received: October 20, 2020; Accepted: November 20, 2020; Published: March 12, 2021

\begin{abstract}
This study analyzed the determinants of food security in the case of Kurmuk district. The study used multi stages sampling techniques to draw representative households. To analyze the data descriptive statistics, Foster, Greer and Thorbeck model and binary logit model were used. The Foster, Greer and Thorbeck food insecurity index was employed to examine the extent and severity of food insecurity. It revealed that $43.6 \%$ of the sample households live below food security line with food insecurity gap and food insecurity severity index of 0.0875 and 0.0352 respectively. Among the sixteen explanatory variables that are included in the binary logit model livestock ownership excluding oxen, oxen ownership, cultivated land size, non-farm income, extension contact and household head educational status showed a significant and positive effect on food security. Whereas household sizes in adult equivalent and household head age have a negative and significant effect on food security. The empirical findings suggest that special attention should be given to improving crop and livestock market, veterinary services, health services, agricultural technologies and creation of awareness on family planning. Interventions like capacity building, agricultural research, agricultural marketing as well as infrastructures that enhance nonfarm activities in sustainable manner need to be designed to reduce food insecurity prevalence in the study area.
\end{abstract}

Keywords: Food Security, Household, Determinants, Foster, Greer and Thorbeck, Binary Logit, Kurmuk

\section{Introduction}

Food is essential in human being's life. Enough food in terms of quantity and quality for all people is an important factor for a nation to continue its development. Lack of food in long terms will lead to hunger and starvation that can cause death. So that enough food is a necessity condition to be well nourished [24]. Food security is much emphasized in international commitments like millennium development goals (MDGs) and sustainable development goals (SDGs). It shows its equal importance for both developed and developing countries. Among prominent international efforts to monitor progress towards MDGs and SDGs, the State of Food Insecurity (SOFI) in the world report by FAO has gained special attention. It shows 815 million people are still undernourished in the world. During 2016 an upward trend is observed in the number of undernourished people around the world. Majority of this population lives in underdeveloped and developing countries [12].

Conflict and insecurity are the main drivers of food insecurity in eighteen countries, and most of food-insecure people across the world have been growing over time [14]. Likewise, food security situation in Ethiopia deteriorated sharply in 2017. In Ethiopia, the number of food-insecure population was increased from 5.6 million in December 2016 to 8.5 million in August 2017 [3]. An expected 3.6 million children and women in Ethiopia were acutely starving in 2017 [20].

In Ethiopia, the poor performance of food security at household level is associated with poor institutional forms and dependency on rain-fed agriculture, which is highly vulnerable to drought which leads to loss of rural household's 
lives and livelihoods in every year [1].

Particularly, poverty and food insecurity are crucial and pertinent problems facing the majority of Ethiopians as the economy is mainly dependent on agriculture which is vulnerable to different shocks, seasonality and trends [6]. The country has been facing challenging problems ranging from those induced by environmental crisis to those caused by demographic and socioeconomic constraints that adversely affect people's production system [27]. Moreover, about 52\% of the rural population and $36 \%$ of the urban population consume under the minimum recommended daily intake of $2100 \mathrm{kcal} /$ person /day [10].

Despite undeniable progress in reducing rates of undernourishment and improving levels of nutrition and health, almost 800 million people are chronically hungry and about 2 billion suffer micronutrient deficiencies [11]. It further predicts that the world will host about 653 million undernourished people even in 2030 if no additional efforts are made to promote pro-poor development. As mentioned in the previous section, Ethiopia has remained to be food insecure for long. Irrespective of the long distance the country has travelled in reducing food insecurity [26]

Numerous studies have confirmed that there is a problem of food insecurity in Ethiopia with wide range of area to be covered and large number of people to be attended for different identified causes of food insecurity problem. Among these causal factors per capita land holding with increasing population growth, livestock availability, education, per capita income of the household from agricultural and non-agriculture activities, soil fertility, conflict, under-funded agriculture are the major and commonly mentioned factors [23].

There are no studies done on assessing such determining factors in this study area. This is mainly because of the fact that socio-cultural, political and economic features might be different from one area to another area and food security determining factors are specific to locations, production and livelihood systems. Therefore this study was ideated the determinants of food security in the rural households of Kurmuk district to narrow the existing information gap and to suggest appropriate policy and development intervention options aimed at reducing food insecurity in the district.

\section{Research Methodology}

\subsection{Description of the Study Area}

This study was conducted in Kurmuk district of Benishangul Gumuz Regional State (BGRS). The region consists of three administrative zones, namely Assosa, Metekel and Kamashi and one special district; it is MaoKomo. Kurmuk is the part of Asossa zone. It is bordered by Sudan in the north and west, Sherkole in the east, Komesha in the southeast, and Assosa in the south. It is $757 \mathrm{Kms}$ away from the capital city of the country, Addis Ababa and $96 \mathrm{kms}$ away from the regional and zonal administrative city Assosa [21].
The total human population of the district is 26,692 out of this 12666 are males and 14026 are females. The total household head of the district is 2525 out of this 2158 are male household heads and 357 are female household heads. Muslim is the major religions of large followers in the district. The livelihood of the people of the study area mainly depends on crop production, traditional gold mining and livestock production [21].

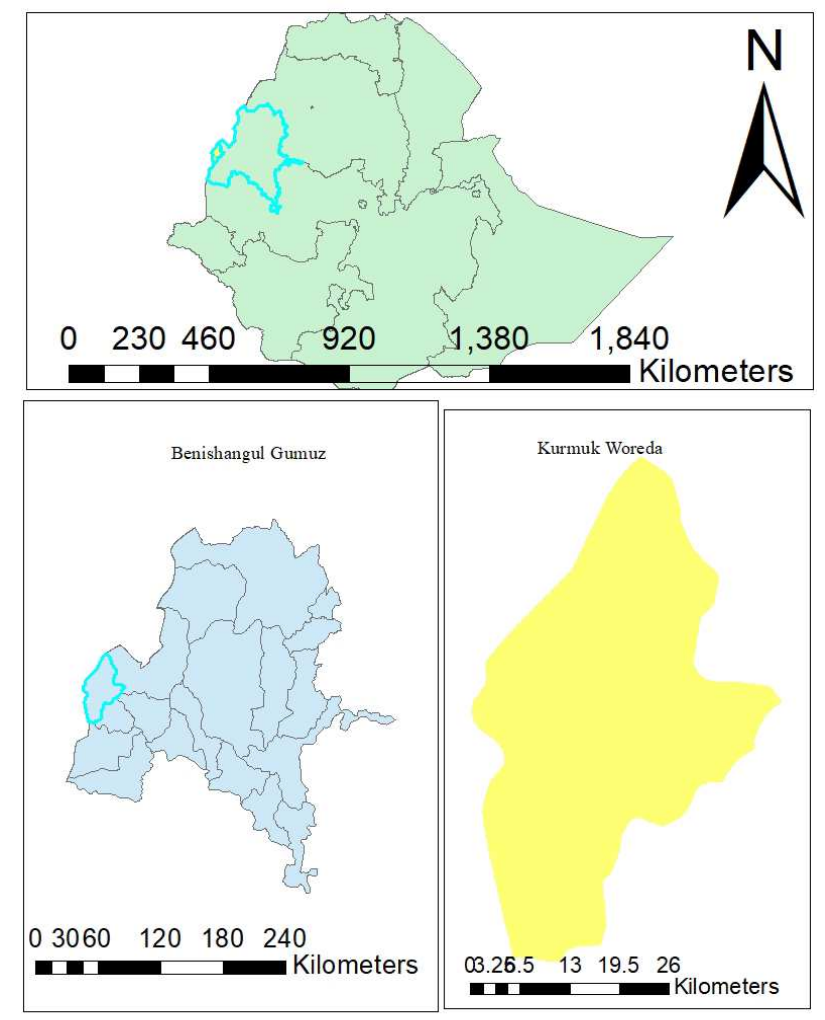

Figure 1. Map of the Study Area.

\subsection{Sampling Techniques and Sample Size Determination}

Therefore, the sample size of this study was determined based on the following formula developed by [28].

$$
\mathrm{n}=\frac{N}{1+N(e)^{2}}
$$

Where $\mathrm{n}=$ sample size, $\mathrm{e}=$ margin of error $=6$ level and $\mathrm{N}$ $=$ total number of rural households in the district $=2515$

$$
\text { Accordingly, } n=\frac{2515}{1+2515(0.06)^{2}}=250
$$

This sample size has enabled the researcher to gather richer data with regard to demographic, socio-economic, institutional and others. So, the selected 250 sample households were interviewed by using semi-structured survey questionnaire.

The study followed two-stage sampling procedure to draw samples representing rural households in the study area. The target population of this study is rural households in Kurmuk district, which are 2515 households [21]. In the first stage simple random sampling technique was involved to select three kebele administrations out of fifteen kebele administrations in the study area. In the second stage, 
probability of proportional sample size was employed to determine the number of households in the selected kebeles and then a lottery method of simple random sampling technique was employed to select all respondent households in the sample kebeles.

\subsection{Sources and Methods of Data Collection}

Both primary and secondary data was used for this study. The primary data was collected from sample rural households through interview using semi-structured questionnaires prepared and pre- tested for its validity and reliability. Information that used to describe geographical location was collected from Kurmuk district agricultural office. The questionnaire was first prepared in English language and then translated into amahric to make questions clear for the enumerator and to facilitate data collection during household survey. For the data collection, three enumerators who speak the local language (rutanegna) and amahric fluently were hired from the study area and they were trained on how to conduct the interview questions and how to approach farmers during the interview. The data was collected under a close supervision of the researchers.

Relevant and necessary secondary information and records for the study was collected through an in-depth review of the relevant published and unpublished documents, worldwide web (www) sources, CSA websites, MoFED and district administration office reports to support the effective implementation of the study. Key informant interview (KII) and Focus group discussion (FGD) also conducted with four household heads on each kebeles to generate qualitative data which supplement the quantitative one.

\subsection{Methods of Data Analysis}

\subsubsection{Measuring Food Security Status of the Households}

The household food security status was measured by direct calories intake method. The principal person responsible for preparing meals was asked how much food was prepared for consumption from purchase, stock and/or gift/loan/wage over a period of time. In this study, a seven-day recall method was used since such a measure gives more reliable information than the household expenditure method [7]. These seven days recall period is selected due to the fact that it is appropriate for exact recall of the food items served for the household within that week. If the time exceeds a week, for instance 14 days, the respondent may not recall properly what he has been served before two weeks [17],

Therefore, the consumption data collected on the basis of seven days recall method were converted into kilocalorie using the food composition table manual adopted from Ethiopian Health and Nutrition Research Institute [9]. Then, in order to calculate the households' daily caloric intake, the total households' caloric intake for the last seven days were divided by seven. The household's daily caloric intake per adult equivalent was calculated by dividing the household's daily caloric intake by the family size after adjusting for adult equivalent using the consumption factor for age and sex categories. Then the results were compared with the minimum subsistence requirement per Adult equivalent (AE) per day of 2,200 Kcal which is set by the Ethiopian Government [22]. Accordingly, this value of minimum subsistence requirement was used as a cut-off point between food secure and insecure households in which case the household is said to be food insecure if it fails to meets this minimum and secure otherwise.

\subsubsection{Descriptive Analysis}

Descriptive statistical tools were employed to explain the food security situation of households with respect to demographic, socio-economic and institutional variables. The specific descriptive statistics used in this study include: tabulation, frequency, percentages, mean, and standard deviation. Statistical tests like t-test and chi-square test were also used to compare food insecure and food secure households in the study area based on different demographic, socio-economic and institutional variables.

\subsubsection{Measurement of the Extent of Food Security}

Many development agencies seek to improve the household food security. That is the objective of targeting is to produce the greatest decrease in the percentage of individual who are food secure. But, targeting is not nearly as straightforward as is often suggested. Indeed it is possible that targeted intervention may be more costly and less effective. As a result, targeting should be assessed against a benchmark, such as the impact on reducing the severity of food insecurity. This problem could easily be handled by using Foster, Greer and Thorbecke (FGT) indices [19].

Even though the model was widely used for poverty measurement studies; several researchers used the FGT model to determine the incidence and severity of food insecurity [4, 13, and 30]. Consequently, to estimate head count ratio, food insecurity gap and to assess the severity of household food insecurity the Foster, Greer and Thorbecke (FGT) index was employed which was widely used for poverty measurement studies.

The class of FGT index was specified as follow:

$$
\mathrm{P}_{\alpha}=\frac{1}{n} \sum_{i=1}^{q}\left[\frac{Z-Y i}{Z}\right\rfloor^{\alpha} ; \text { if } \mathrm{yi}>\mathrm{z} \text { then } \mathrm{z}-\mathrm{yi}=0
$$

Where: $\mathrm{n}$ is the number of sampled households,

$\mathrm{q}$ is the number of food insecure households,

$\mathrm{z}$ represents the cut-off between food security and food insecurity where in this case $2200 \mathrm{kcal} / \mathrm{AE} / \mathrm{day}$, yi is a measure of per adult equivalent food calorie intake of the $i^{\text {th }}$ household $\alpha$ is the weight attached to the severity of food insecurity.

Most commonly $\alpha$ is assumed to take the values of 0,1 and 2. Giving no weight to the severity of food insecurity is equivalent to assuming that $\alpha=0$. This index does not show the depth of food insecurity below the recommended minimum calorie requirement or do not capture differences among the food insecure households. That is, it does not tell whether the food insecure is only slightly or substantially below the minimum recommended level of calorie intake of 
2,200kcal/AE/day [19]. Then, the formula collapses to:

$$
\mathrm{P}_{0}=\frac{q}{n}
$$

The above formula is called head count ratio ( $\mathrm{P} 0$ ). It shows the proportion of households below the commonly accepted minimum level of per capita household calorie intake. Giving equal weight to the severity of food insecurity among all food-insecure households is equivalent to assuming that $\alpha=1$. Then the formula collapses to (P1):

$$
\mathrm{P}_{1}=\frac{1}{n} \sum_{i=1}^{q} \frac{Z-Y i}{Z}
$$

The above formula is called food insecurity gap (P1) and it measures how far the food insecure households, on average, are from the minimum recommended level of calorie intake. Therefore, it shows the calorie, as percentage of minimum recommended level, which is required to bring each of the food insecure individuals to the line. That is, the total amount of increase in food security needed to eliminate food insecurity among all food insecure households which is calculated by adding up the caloric shortfall of all individuals for whom availability is less than the requirement. To focus on the most food insecure households the best way is using the third measure known as severity of food insecurity gap (P2). Here $\alpha=2$. This index gives those further away from the given minimum energy requirement level a higher weight in aggregation than those closer to meet the daily recommended energy level [19]. Then, the severity of food insecurity is specified as follows:

$$
\mathrm{P}_{2}=\frac{1}{N} \sum_{i=1}^{Q}\left[\frac{Z-Y i}{Z}\right]^{2}
$$

\subsubsection{Econometric Method}

Choosing an appropriate model and analytical technique depends on the type of variable under investigation. Ordinary least squares method deals with cases where the dependent variable of interest is a continuous variable. But in many applications, the dependent variable of interest is not a continuous scale; it may have only two possible outcomes. Similarly, in this study, the dependent variable Y (household food security) is dichotomous variable taking value 1 if the household is food secure and 0 otherwise. In the case where the dependent variable is dichotomous, probability regression models are the most fitting to study the relationship between dependent and independent variables. In the case where the response variable is qualitative, it is the probability of the dependent variable given independent variable that is determined. The most common qualitative regression models are linear probability model, logit model, and probit model [16]. Linear probability model like a typical linear regression model, determine the conditional expectation of the dependent variable given independent variable. Beside this, the model is encountered with many problems like nonnormality and heteroscedastic variances of the disturbance Ui and the probability fails to fall in between 0 and 1 values. For this reason, linear probability model is not attractive model and it is fallen out of use in many practical applications.
These problems could be easily solved by using probit and logit models. In these two models the probability will fall in between 0 and 1 . In most applications these two models are quite similar. The main difference being the logistic distribution has slightly fatter tails, that is to say, the conditional probability $\mathrm{Pi}$ approaches zero or one at a slower rate in logit than in probit. Therefore, there is no compelling reason to choose one over the other. In practice many researchers choose the logit model because of its comparative mathematical simplicity [16]. Therefore, in this study logit model is chosen for its simplicity and less complexity of its interpretation. Then, following logit model is specified as follows [16]:

$$
\mathrm{P}_{\mathrm{i}}=\mathrm{E}(\mathrm{Y}=1 / X i)=\frac{1}{1+e^{-(\beta 0+\beta i X i}}
$$

For ease of exposition, the probability that a given household is food secure is expressed as:

$$
\mathrm{P}_{\mathrm{i}}=\frac{1}{1+e^{-Z i}}
$$

The probability of being food insecure is 1-Pi:

$$
1-\mathrm{P}_{\mathrm{i}}=\frac{1}{1+e^{-Z i}}
$$

Thus:

$$
\frac{P i}{1-P i}=\frac{1+e^{z i}}{1+e^{-z i}}=e^{z i}
$$

The ratio of the probability that a household would be food secure to the probability of that it would be food insecure. It is the odds ratio in favor of food security. Taking the natural log of equation (9) we have:

$$
\mathrm{L}_{\mathrm{i}}=\ln \frac{P i}{1-P i}=\mathrm{Z}_{\mathrm{i}}=\beta_{0}+\beta_{1} \mathrm{X}_{1}+\beta_{2} \mathrm{X}_{2}+\ldots \ldots+\beta_{\mathrm{n}} \mathrm{X}_{\mathrm{n}}
$$

Where, Pi is the probability that the household would be food secure ranges from 0 to 1 and $\mathrm{Zi}$ is a function of $\mathrm{n}$ explanatory variable and is expressed as:

$$
Z_{i}=\beta_{0}+\beta_{1} X_{1}+\beta_{2} X_{2}+\ldots \ldots+\beta_{n} X_{n}
$$

Where, $\beta 0$ is an intercept and $\beta 1, \beta 2 \ldots . . \beta n$ are the slopes of the equation and $\mathrm{Li}$ is logs of odds ratio in favor of food security which is not only linear in parameters but also linear in terms of explanatory variables. If the disturbance term Ui is introduced, the logit model would become:

$$
\mathrm{Z}_{\mathrm{i}}=\beta_{0}+\beta_{1} \mathrm{X}_{1}+\beta_{2} \mathrm{X}_{2}+\ldots \ldots+\beta_{\mathrm{n}} \mathrm{X}_{\mathrm{n}}+\mathrm{Ui}
$$

\subsubsection{Definitions of Variables and Working Hypothesis}

Once the analytical procedure and its requirements are known, it is necessary to identify the potential independent variables and describe their measurements. Different variables are expected to affect food security in the study area. The major variables that are expected to have influence on the household food security are presented and explained below.

Household food security status: It is a dichotomous 
dependent variable in the model taking value 1 if the household is food secure and 0 otherwise. Households' food security status was determined by comparing total kilocalories consumed in household per adult equivalent per day with the daily minimum requirement of $2200 \mathrm{kcal} / \mathrm{AE} /$ day. Households who fail to get $2200 \mathrm{kcal} / \mathrm{AE} / \mathrm{day}$ were considered as food insecure and otherwise food secure.

The independent variables of the model: The independent variables that are hypothesized to have association with Food security status used for binary logit regression was selected based on economic theories and the past research findings related to the study. Any exogenous variable having negative coefficient is expected to increase food insecurity whereas explanatory variable found to be positively related to the food security status was increase the wellbeing of the households by increasing the food security of the households. Economic theories, past research findings, experts and author's knowledge of the food security status and situation of the study area were used to identify the potential determinants of household food security in the study area.

Age of head of household: Older people have relatively richer experiences of the social and physical environments as well as greater experience of farming activities [18]. That is, when household heads get older, they are expected to have stable economy in farming. Moreover, older household heads are expected to have better access to land than younger heads, because younger men either have to wait for land redistribution, or have to share land with their families.

Household size: This is the total number of family members that live under the same household and adjust to adult equivalent. The expectation is that the household with large number of children or economically dependent family members will face food insecurity because of high dependency burden. The existence of large number of children under age of 15 and old age of 60 and above in the family could affect the food security status of the household. This means the working age population (i. e., 15-64 years) supports not only themselves, but also additional dependent persons in the family. Thus, it is hypothesized that the family with relatively large number of dependent family members (high dependency ratio) negatively affects household food security status.

Sex of the household head: This is femaleness or maleness of the total family members. It is hypothesized that, femaleheaded households are expected to be more food insecure than male- headed households.

Education status of household head: This stands for educational level of the rural household head by categorizing into literate and illiterate. It takes a value of 1 if the household head is litrate and zero otherwise. The impact of education on household food production might be through promoting awareness on the possible advantages of modernizing agriculture through technological inputs and by diversifying household incomes, which in turn enhance household's supply. Households led by non-literate heads are less likely to understand modern farming technologies provided to them through any media like extension workers, radio and others than literate household heads. The covariate education assumed binary values and is expected to have a positive influence on household food security status.

Livestock ownership excluding oxen: The livestock holding of the household was measured by the number of Tropical Livestock Unit (TLU). Livestock contribute to household's economy in different ways, for instance, as a source of pulling power, source of cash income, source of supplementary food, and means of transport. Besides, livestock are considered as a means of security and means of coping during crop failure and other calamities [18]. Therefore, it hypothesizes that a higher number of TLU will increase the probability of the household to be food secure. That is, as TLU increases food insecurity of the household will be reduces. So, Positive correlation is expected between livestock ownership and household food security status.

Number of oxen ownership: Number of ploughing oxen is another determinant of the food security status of households. Oxen serve as a source of traction in many developing countries, thereby significantly affecting household's crop production. Animal traction power enables households to cultivate greater source of land and to execute agricultural operations timely [18]. Therefore, it is hypothesized that a positive relationship between oxen ownership and food security of the household.

Cultivate land size of the household: This refers to continuous variable and represents the total area of land in hectares cultivated by the household. Total cultivated land owned by household is important resource for food production. Hence, it is expected to be associated with food security status. It is hypothesized that farmers who have larger farm landholding would have less probability to be food insecure.

On-farm income: The on-farm income refers to total annual earnings of the household from sales of agricultural product. It was measured by the amount of birr obtain from sales of crop product, livestock and livestock products. This is expected to be used to purchase consumable goods, some agricultural inputs, and also to fulfill social financial obligations. Therefore, it was hypothesized that on-farm income has positive effect on food security status of households in the study area.

Off-farm income: When crop production and income earned from sales of livestock and livestock products become inadequate to subsist the farming households of the study area they often depend on external or other source of income to purchase food and farm inputs. So income earned from off farm activities is an important variable, which determines household food security in the study area. In this regard, households engaged in off-farm activities are better endowed with additional income and less likely to be food insecure. Therefore, off-farm income per AE is expected to positively associate with household food security status.

Household Health: presence of seriously ill family member, it is dummy for 1 if the household had one or more seriously ill member 12 months prior to the administration of 
the questionnaire and 0, otherwise. Household labour is often one of the few means of earning income the rural people can rely upon. Lack of good health will make people to become weak and unproductive. Given the strong seasonal nature of agricultural activities timing of performing tasks is very important to result in reasonable yields. The expectation is that if illness strikes, not only working days are lost, but also part of saving will be spend for medical treatment, as a result of which the probability of being trapped in food insecurity is likely to rise.

Use of modern agricultural inputs: Dummy for use of agricultural inputs at a recommended rate: 1 if the household use inputs at a recommended rate and 0 , otherwise. The expectation is that households use modern agricultural inputs at a recommended rate obtain high crop yield, and hence, have broader opportunity of being better off.

Access to credit: Refers to the access of household for institutional credit service which is dummy variable, that means 1 if the household takes credit and 0, otherwise. The expectation is that those households having access to credit have better chance of involving in non-farm activities, purchasing ploughing oxen etc... as a result of which households can increase and diversify their income and improve their food consumption.

Extension contact: This is a dummy variable which measures visiting of rural household by extension agents. This may be explained by the factors that the message that households' gains from extension agents help them to initiate to use newly released and highly productive inputs for the farmers. In this study also hypothesizes that of extension visit rural households decrease rural households food insecurity.

Distance from market center: This refers to the closeness of the household village to the nearest market center measured in kilometers or time. Access to market to their agricultural product and other public infrastructure may create opportunities of more income by providing non-farm employment and easy access to inputs and transportation. It was hypothesized, that households who have good accessibility to market center have better chance to improve farm household food security status than who do not have a proximity to market centers. Hence, distance to market center is expected to be negatively related to food security.

Dependency ratio: Household members aged below 15 and above 64 are considered as dependent and dividing it by household members whose age is between 15 - 64 resulted in dependency ratio. These groups are economically inactive and burden to the other member of the household. It is hypothesized that dependency ratio and food security are negatively related.

Marital status of household head: Marriage is biological and social engagement to support each other both socially and economically. Marriage is established with a view of helping each other and married people pool their resources and also reduce cost that would have been spent separately. Moreover, married households put aside some of resources for unforeseen circumstances to smoothen their life. In this study marriage and food security are hypothesized to be related positively.

Table 1. Definition of Variables and Hypothesized Relationships.

\begin{tabular}{|c|c|c|c|}
\hline Variables & Type & Measurement & Expected sign \\
\hline Household head age & Continuous & Years & $+/-$ \\
\hline Household size & Continuous & Adult equivalent & -- \\
\hline Household head Sex & Dummy & $1=$ if male, $0=$ otherwise & + \\
\hline Dependency ratio & Continuous & Number & -- \\
\hline Household head Marital Status & Dummy & $1=$ married, $0=$ otherwise & + \\
\hline Education of household head & Dummy & $1=$ literate, $0=$ otherwise & + \\
\hline Health of the household & Dummy & $1=$ if the household has not health problem, $0=$ otherwise & + \\
\hline Total size of cultivated land & Continuous & Hectare & + \\
\hline The number of oxen owned & Continuous & Number & + \\
\hline Total livestock owned except oxen & Continuous & TLU & + \\
\hline Use of modern agricultural inputs & Dummy & 1 if the household use modern agricultural inputs, 0 otherwise & + \\
\hline On-farm income & Continuous & ETB & + \\
\hline Household off-farm and non-farm income & Continuous & ETB & + \\
\hline Household credit utilization & Dummy & 1 , credit utilizer, 0 otherwise & + \\
\hline Extension contact & Dummy & 1 , households visit by extension agents, 0 otherwise & + \\
\hline Distance from market center & Continuous & Minutes & \\
\hline
\end{tabular}

\section{Result and Discussion}

\subsection{Food Insecurity Indexes of Rural Households}

The food security line is used to estimate the food insecurity indexes in the study area. Accordingly, the food insecurity indices were calculated using the FGT measures and found out to be 0.436 for head count, 0.0875 and 0.0352 for food insecurity gap and food insecurity severity, respectively (Table 2 ).
Head count index measures the percentage of the sampled households whose calories intake was less than the food security line. The head count index of the study area was 0.436 , which implies 43.6 percent of the sampled households in the district are below the food security line.

Food insecurity gap index estimates the total resources needed to bring all the food insecurity to the level of the food security line and also cover the extent to which individual calories intake falls below food security line. The survey result indicates that the food insecurity gap index is 0.0875 , which implies food insecurity households on average 192.5 
kilocalories, was required to bring every food insecurity household up to food security line.

The food insecurity severity index measures variation in the poverty level of individual households. The survey result indicates that $3.52 \%$ variation among food insecure households in the study area.

Table 2. Food Insecurity Indices of Sampled Rural Households.

\begin{tabular}{lll}
\hline Head count index (Po) & Food Insecurity gab index (P1) & Food Insecurity severity index (P2) \\
\hline 0.436 & 0.0875 & 0.0352 \\
\hline
\end{tabular}

\subsection{Socio-economic Characteristics of Households Across Food Security Status}

\subsubsection{Socio-Economic Characteristics of Continuous variables Across Food Security Status}

Household size: The average family size of the sample households was 4.26 with a minimum and maximum household sizes were 0.75 and 11.95 in adult equivalents respectively. The survey result revealed that $57.2 \%$ of the households have a household size of below average and $42.8 \%$ of the households have a household size of above average. However the $\mathrm{F}$ test indicated that there is significant difference in mean of household size between the food secure and food insecure households.

Age of household head: The survey revealed that the age of the respondents ranged from 20-93 years with the average age of 49.78 years. The mean age of food insecure (55.12) was greater than the mean age of food secure (45.66). Younger households are usually better than older households. This is because productivity of the individual declines and the individual has a small amount of savings to compensate for the decline of productivity and income. In addition the ttest revealed there is significant difference in age of the food secure and food insecure at $\mathrm{P}<0.01$.

Dependency ratio: The mean dependency ratio of sample household was 0.38 . This means every 100 persons within the economically active population groups support not only themselves, but also supporting an average of 38 dependent household members with all basic necessities. The t-test indicated that there is no significant difference in mean of dependency ratio between the food secure and food insecure households.

Table 3. Household Characteristics Across Food Security Status with Respect to Continuous Variables.

\begin{tabular}{|c|c|c|c|c|c|c|}
\hline \multirow{3}{*}{ Variables } & \multicolumn{5}{|c|}{ Food security status } & \multirow{3}{*}{ t-value } \\
\hline & \multicolumn{2}{|c|}{ Food insecure } & \multicolumn{2}{|c|}{ Food secure } & \multirow{2}{*}{$\begin{array}{l}\text { Total household } \\
\text { Mean } \\
\end{array}$} & \\
\hline & Mean & St. Dev. & Mean & St. Dev. & & \\
\hline HHSZAE & 4.8266 & 2.03638 & 3.9594 & 1.63230 & 4.34 & $3.737 * * *$ \\
\hline HHAGE & 55.12 & 13.981 & 45.66 & 15.510 & 49.78 & $4.990 * * *$ \\
\hline DEPR & 0.3929 & 0.21492 & 0.3623 & 0.23421 & 0.38 & 1.061 \\
\hline LANDSZ & 2.53 & 2.82284 & 2.99 & 2.12459 & 2.79 & -1.460 \\
\hline LIVEST & 2.04 & 2.08002 & 4.18 & 3.36378 & 3.25 & $-5.846 * * *$ \\
\hline OXEN & 0.22 & 0.599 & 1.11 & 1.141 & 0.724 & $-7.421 * * *$ \\
\hline ONFAIN & $6,562.06$ & $11,102.12$ & $11,137.4$ & $9,555.19$ & 9142.56 & $-3.497 * * *$ \\
\hline NFINCO & $5,087.09$ & $10,712.05$ & $11,657.5$ & $16,810.72$ & 8792.83 & $-3.559 * * *$ \\
\hline DSTMKT & 38.94 & 29.42324 & 40.5816 & 29.68649 & 39.86 & -0.436 \\
\hline
\end{tabular}

Note: $* * *, * *$ and $*$ Significant at $\mathrm{p}<0.01, \mathrm{P}<0.05$ and $\mathrm{p}<0.1$ probability level respectively

Source: Own survey result, 2020

Household land size: As indicated in the table 3 the mean land size owned by the sample households was 2.79 hectares. The minimum and maximum land size of the sample respondents were 0 and 20.25 hectares respectively. The survey result shows $71.64 \%$ of households own land size of less than the mean land size of 2.59 hectares, while $28.36 \%$ of the respondents own more than the mean land sizes. Small land holdings influence the consumption behavior of households as farm households face shortage of land to grow more types of crops to ensure the availability of food grain at different periods of a year. But the statistical analysis showed that there is no significant difference in size of cultivated land between the food secure and food insecure households.

Livestock owner ship: livestock species that are generally kept to make-up the livestock resources in the woreda include cattle, sheep, goat and hens. The average numbers of livestock holding of the sample respondents were 3.25 in TLU. The minimum and maximum TLU of the sampled respondents were 0 and 14.13 respectively. Livestock are an important source of income, and they are most important insurance to increase access of quality foods (like dairy products, meat and egg). Additionally the t-test presented a significant difference between the food secure and food insecure households in terms of TLU owned at $1 \%$ significance level.

Oxen owner ship: Number of oxen possession helps to undertake farm activities easily, on time and also allow in managing other farm activities. Besides, well ploughed farm could produce better and secures family food requirement. The mean oxen for the sampled respondents were 0.72 . For food secure and food insecure households the average oxen are 1.11 and 0.22 respectively. The $\mathrm{t}$ - test indicates that number of oxen associated with food security status is significantly at 1 percent probability level.

On farm income: The mean values of annual households' on farm income for food secure households were 11,137.4 
ETB and for food insecure households were 6,562.06ETB. The average annual households' on farm income for the surveyed households was 9142.56ETB. The study result shows that there is statistical significance mean difference between food secure and food insecure households based on average annual households 'on farm income.

Nonfarm income: The average annual households' non farm income for the surveyed households was 8792.83ETB. The study result shows that there is a significance difference between food secure and food insecure households based on average annual households' non farm income with t-value at 1 percent probability level of significance.

Market distance: The mean distances from market per minute for respondents were 39.86 minutes. For food secure and food insecure households the average distance from market per minute is 40.58 and 38.94 minutes respectively. The $\mathrm{t}$ - test indicates that distance from market associate with food security status is not significant.

Table 4. Household Characteristics Across Food Security Status with Respect to Dummy Variables.

\begin{tabular}{|c|c|c|c|c|c|c|c|c|}
\hline \multirow{3}{*}{ Variables } & \multirow{3}{*}{ Category } & \multicolumn{6}{|c|}{ Poverty status } & \multirow{3}{*}{$x^{2}$ value } \\
\hline & & \multicolumn{2}{|c|}{ Food insecure (109) } & \multicolumn{2}{|c|}{ Food secure (141) } & \multicolumn{2}{|c|}{ Total household } & \\
\hline & & Freq. & $\%$ & Freq. & $\%$ & Freq. & $\%$ & \\
\hline \multirow{2}{*}{ SEX } & Male & 89 & $35.6 \%$ & 120 & $48 \%$ & 209 & $83.6 \%$ & \multirow{2}{*}{0.5352} \\
\hline & Female & 20 & $8 \%$ & 21 & $8.4 \%$ & 41 & $16.4 \%$ & \\
\hline \multirow{2}{*}{ HHMS } & Unmarried & 15 & $6 \%$ & 20 & $8 \%$ & 35 & $14 \%$ & \multirow{2}{*}{0.0091} \\
\hline & married & 94 & $37.6 \%$ & 121 & $48.4 \%$ & 215 & $86 \%$ & \\
\hline EDUSTA & Illiterate & 52 & $20.8 \%$ & 85 & $34 \%$ & 137 & $54.8 \%$ & $3.9261 * *$ \\
\hline \multirow{2}{*}{ CREDITUTI } & Utilize & 19 & $7.6 \%$ & 31 & $12.4 \%$ & 50 & $20 \%$ & \multirow{2}{*}{0.7971} \\
\hline & Not utilize & 90 & $36 \%$ & 110 & $44 \%$ & 200 & $80 \%$ & \\
\hline \multirow{2}{*}{ НHН } & Yes & 49 & $19.6 \%$ & 45 & $18 \%$ & 94 & $37.6 \%$ & \multirow{2}{*}{$4.4549 * *$} \\
\hline & No & 60 & $24 \%$ & 96 & $38.4 \%$ & 156 & $62.4 \%$ & \\
\hline \multirow{2}{*}{ EXTCONT } & Yes & 64 & $25.6 \%$ & 105 & $42 \%$ & 169 & $67.6 \%$ & \multirow{2}{*}{$6.9649 * * *$} \\
\hline & No & 45 & $18 \%$ & 36 & $14.4 \%$ & 81 & $32.4 \%$ & \\
\hline AGINPU & Yes & 71 & $28.4 \%$ & 114 & $45.6 \%$ & 185 & $74 \%$ & $7.8894 * * *$ \\
\hline
\end{tabular}

Note: $* *$ and $* * *$ significant at $\mathrm{p}<0.05$ and $\mathrm{p}<0.01$ respectively

Source: own survey result, 202

\subsubsection{Socio-Economic Characteristics of Categorical Variables across Food Security Status}

Sex of Household Head: Based on table 3 among 250 sample households, $209(83.6 \%)$ were male headed households; whereas $41(16.4 \%)$ were female headed households. 42.58 percent of male headed households and 48.78 percent of female headed households are living below food security line (2200 kcal. per day per adult equivalent). As far as sex ratio of the household head is concerned, male headed households are greater than female headed households. From food insecure households, $81.65 \%$ were male-headed, and $18.35 \%$ were female-headed and from food secure households, $85.1 \%$ were male-headed, and $14.9 \%$ were female-headed. The chi-square test of association of sex of household head and food security status is not significant.

Marital Status: $86 \%$ of the total sample household heads are married while $14 \%$ are unmarried. $86.2 \%$ of food insecure household heads and $85.82 \%$ of food secure household heads were married. The chi-square test indicates that household head marital status associated with food security status is not significant.

Educational Status: Education prepares individuals with the necessary knowledge of how to make a living. It promotes awareness about the possible advantages of modern agriculture and the use of technological inputs and diversifying household income sources. $54.8 \%$ of the total sample household heads are illiterate while $45.4 \%$ are literate. $47.7 \%$ of food insecure household heads and $60.3 \%$ of food secure household heads were illiterate. The chi- square test indicates that household head educational status associated with food security status is significant at 5\% level of significance.

Credit utilization: From total sampled respondents' $80 \%$ of household have not taken credit and the remaining $20 \%$ of households were take credit. The survey results showed that majority of the sampled households in the study area were not take credit. 38 and 45 percent of the credit utilizer and non-credit utilizer household heads are living below food security line respectively. The chi-square test indicates that credit utilization is associate with food security status is not significant.

Health Status: More than anything else health is the first and single factor for the well/ bad being of individuals. Without proper health life is difficult. From the total sample households $37.6 \%$ were one or more of the household member ill seriously. While $62.4 \%$ of the total sample households were not serious health problem. 52.13 percent of the households that have serious health problem and $38.46 \%$ of the households that have not serious health problem households are living below food security line.

The chi-square test indicates that household health status associated with food security status is significant at $5 \%$ probability level.

Extension Contact: From the total sampled households $67.6 \%$ were visiting by extension agent while $32.4 \%$ didn't. $37.87 \%$ of households that are visiting by extension agent and $55.56 \%$ of households that are not visiting by extension agent were food insecure. The chi-square test indicates that 
extension contact associated with food security status is significant at $5 \%$ level of significance.

Use of modern agricultural input: $26 \%$ of the total sample households have not utilized improved agricultural input while $74 \%$ have utilized. $38.38 \%$ of modern agricultural input utilizer households and $58.46 \%$ of non-utilizer households were food insecure. The chi-square test indicates that utilized improved agricultural input associated with food security status is significant at $5 \%$ probability level. Improved agricultural input includes utilization of improved seed, fertilizer, pesticide and herbicide.

\subsection{Determinants of Rural Households Food Security Status}

Binary logit model was employed to answer the question "what are the factors that affect rural households' food security status." The result of the model indicated that household size, age of household head, cultivated land size, tropical livestock unit, oxen ownership, extension contact, annual household nonfarm income and education status were found to be significant in determining rural households' food security status. Except household size and age of household head all other variables like cultivated land size, tropical livestock unit, oxen ownership, extension contact, annual household nonfarm income and education status affect rural households' food security status positively and significantly.

Household size was significant at $1 \%$ probability level and negatively related with the state of food security. Negative relationship indicates that the favor of the probability of being food secure decreases with an increase in the household size measured in adult equivalent. The marginal effect of family size -0.1797 indicates that the probability of being food secure will decrease by approximately 17.97 percent with one additional family member in adult equivalent. The result indicated that larger household size tends to be food insecure compared to smaller household size. The possible explanation is that those households who depend on limited productive resources will face food insecurity by increasing household size. Moreover, land size scarcity and degradation of cultivable land are common problems of the study area. This result is in conformity with the findings of [2-5].

Age of household heads had significant at one percent probability level and negative relationship with the household food security status. Other variables remaining constant, increased in the age of the household head by one year, decreased the probability that the household was food secure by 1.5 percent. The negative relationship implies that older age household heads have less chance to be food secured than younger ones. This is possible because older household heads are less productive and they lead their life by remittance and gifts. They could not participate in other income generating activities. On the other hand, older households have large number of families and their resources were distributed among their members.

Land size owned by household heads was found to have significant at $10 \%$ level of significance and positive relationship with food security status of households suggesting the larger the land size, the better food secure status of the household. Other variables remaining constant, increased in cultivated land by one hectare, increased the probability that the household was food secure by 3.1 percent. The possible explanation was that, when cultivated land increased, households would be able to minimize its production risks or would be able to produce more which in turn helped to reduce food insecurity problem of his family. This result was in conformity with the works of [30].

Livestock owned by the household head (TLU) was significant at $1 \%$ level of significance and positively related with households food security status. The model result indicated that those who had better livestock ownership measured in TLU were food secure than those with lower number of livestock. Other variables remaining constant, increased in the number of livestock holding in TLU, increased the probability that the household was food secure by 8.3 percent. The possible explanation was the fact that, households with large number of livestock in tropical livestock unit had better chance of earning more income from livestock production. This in turn helped households to buy foods when they faced shortage and invested for the purchase of farm input which increased production and thus ensuring food security at the household level. The household having larger size of livestock can have better food security status, and therefore the possession of more livestock imply the higher likelihood of food security. This finding is consistent with the result of other studies [15]

Non-farm income was found to have significant at 5\% level of significance and positive relation with the food security status of the household indicating farmers engaged in non-farm activities have better chance to be food secure. This might be due to the fact that households engaged in nonfarm activities are better endowed with additional income and more likely to escape food insecurity. Other variables remaining constant, increased in the number of non-farm income by one birr, increased the probability that the household was food secure by 2.1 percent. This finding is consistent with the finding of food security authors [25-29].

Number of oxen owned was found significant at one percent probability level and had positive relationship with the household food security status. Other variables remaining constant, increased in the number of oxen owned by one, increased the probability that the household was food secure by 18.78 percent. The possible explanation was that oxen as the most traction power in the area, helped households to produce more by themselves or to earn income by renting their oxen to others which in turn helped households to access food. Similar result was also obtained by [30].

Education level of household head affects food security situation positively and significantly at $10 \%$ probability level. The positive relationship indicates that literate households are less food insecure than illiterate households. The possible explanation is that household head education largely 
contributed on working efficiency, competency, diversify income, adopting technologies and becoming visionary in creating conducive environment to educate dependents with long term target to ensure better living condition than illiterate ones. This is due to educated household head plays a significant role in shaping household members. Thus, being literate increased the chance of becoming food secure in the sample households. The marginal effect of the variable reveals that for literate households the probability of being food secured increased by $15.85 \%$.

Extension contacts affects food security situation positively and significantly at $1 \%$ probability level. The possible explanation is the message that household' gains from extension agents help them to initiate to use newly released and highly productive inputs for the farmers. The marginal effect of the variable reveals that for households who contact with extension agent the probability of being food secured increased by $26.25 \%$.

Table 5. Results of Binary Logistic Regression Model.

\begin{tabular}{|c|c|c|c|c|}
\hline Variables & ME (dy/dx) & Coef. & $\mathbf{z}$ & $\mathbf{P}>\mathbf{z}$ \\
\hline HHSZAE & -0.1797283 & $-0.8800622 * * *$ & -5.44 & 0.000 \\
\hline DEPR & 0.0626948 & 0.3069929 & 0.34 & 0.737 \\
\hline HHAGE & -0.0153479 & $-0.0751528 * * *$ & -4.47 & 0.000 \\
\hline LANDSZ & 0.0311159 & $0.1523627^{*}$ & 1.87 & 0.062 \\
\hline ONFAINC & $4.28 \mathrm{e}-06$ & 0.000021 & 1.20 & 0.229 \\
\hline LIVEST & 0.0832799 & $0.4077905 * * *$ & 2.91 & 0.004 \\
\hline NFINCOM & $8.59 \mathrm{e}-06$ & $0.0000421 * *$ & 2.52 & 0.012 \\
\hline ACRE & -0.0635467 & -0.3111644 & -0.62 & 0.534 \\
\hline НHН & 0.0686045 & 0.3359308 & 0.90 & 0.367 \\
\hline DSTMKT & 0.0009156 & 0.0044832 & 0.63 & 0.526 \\
\hline EXTCONT & 0.2625222 & $1.285473 * * *$ & 2.75 & 0.006 \\
\hline AGINPU & 0.0346404 & 0.1696213 & 0.36 & 0.719 \\
\hline MARITAL & -0.1548031 & -0.8881715 & -1.14 & 0.254 \\
\hline EDUCATION & 0.1585279 & $0.7762516^{*}$ & 1.65 & 0.098 \\
\hline Number of obs. & 250 & & & \\
\hline LR chi2 (16) & 143.14 & & & \\
\hline Prob $>$ chi 2 & 0.0000 & & & \\
\hline Log likelihood & -99.665592 & & & \\
\hline Pseudo R2 & 0.4180 & & & \\
\hline
\end{tabular}

\section{Conclusion and Recommandation}

\subsection{Conclusion}

The incidence of food insecurity is widespread among the surveyed households $(43.6 \%), 0.436$ the head count ratio, 0.0875 poverty gap, and 0.0352 as the severity index in the study area respectively calls for urgent interventions aimed at curbing the fate of the food insecure households. One way of doing this is studying the determinants of food security by informing concerned parties as the factors are important in fighting against food security problems. Without the clear identification of the factors that account for the periodic or continuous impoverishment of life in the area it is really absurd to come up with concrete solutions. As rural food insecurity, per see, is a multitude of interrelated factors-a cause being a consequence simultaneously, critical identification of the variables is important. However, because it is difficult to bring panaceas for the whole problems over night prioritization of the variables is of paramount importance.

\subsection{Recommandations}

To make considerable reductions on level of rural household poverty status in Kurmuk district the following measures and actions should be taken by the concerned bodies. The possible areas of intervention that emanate from the results of this study are presented as follows:

a. Serious attention should be given to limit the increasing population size in the study area. In order to minimize such effects, provide education of couples about family planning by the concerned bodies.

b. Government policies should increase access to nonfarm activities for all rural households, particularly for households with little land resources and monetary assets.

c. Improved agricultural technologies that enhance the productivity of land per unit area and training of farmers on land management should be developed.

d. The concerned bodies should improve productivity and production of livestock through provision of veterinary services, developing irrigable rangelands, improving the management practice and use of improved breeds.

\section{Conflicts of Interest}

The author declares no conflicts of interest.

\section{Acknowledgements}

The authors are thanks to Assosa University for providing financial support in the research work. We also genuinely 
thank the local communities in our research area, Bambasi district, and all the enumerators for their valuable efforts.

\section{References}

[1] Abduselam A (2017). Food Security Situation in Ethiopia: A Review Study. Int. J. Health Econo Polic. 12: 86- 96.

[2] Abebaw S. (2003). Dimensions and Determinants of Food Security Among Rural Households in Dire Dawa, Eastern Ethiopia. An M. Sc. Thesis presented to the School of Graduate Studies of Alemaya University, Alemaya. 152p.

[3] ACAPS (2018). Food insecurity. Retrieved from https://www.acaps.org/sites/acaps/files/slides/files/20180226 acaps_thematic report. food insecurity final pd

[4] Aschalew F. (2006). Determinants and Dimensions of Household Food Insecurity in Dire Dawa City, Ethiopia an M. Sc. Thesis presented to the School of Graduate Studies of Alemaya University. Pp 64.

[5] Ayalew Y. (2002). Identification and Intensity of Food Insecurity and Coping Strategies of Rural Household in the North Shewa, the Case Of Lalomama. Thesis presented to the school of Graduate student of Alemaya University.

[6] Bedemo, A. Getnet, Kindie; Kassa, B.; Chaurasia,. P. (2014). The role of rural labor market in reducing poverty in West Ethiopia. J. Develop. Agricult. Vol: pp-pp.

[7] Bouis H. (1993). Food consumption surveys: How random are measurement errors? In: J. von Braun and D. Putez. Data needs for food policy in developing countries. IFPRI, Washington DC.

[8] CSA (Central statistical agency) (2014) Ethiopia mini demographic and health survey report, Addis Ababa, Ethiopia

[9] EHNRI (Ethiopian Health and Nutrition Research Institute). (1997). Food Composition Table for Use in Ethiopia. Addis Ababa, Ethiopia.

[10] FAO (2012). FAO crop and food security assessment mission to Ethiopia. Special report. P 25-30. Available online at www.fao.org

[11] FAO (2016) Regional Overview of Food Insecurity: Asia and the Pacific. FAO, Bangkok (Thailand). Regional Office for Asia and the Pacific.

[12] FAO I. W. IFAD. UNICEF (2017). The State of Food Security and Nutrition in the World 2017. Building Resilience for Peace and Food Security. Rome: FAO. Accessed 10: 07.

[13] Frehiwot F. (2007). Food Insecurity and its Determinants in Rural Households in Amhara Region. Msc Thesis, Department of Economics, Fuculty of Business and Economics, School of Graduate Studies, Addis Ababa University, Ethiopia.

[14] FSIN (2018). Global Report on Food Crises. Retrieved from http://www.fao.org/emergencies/resources/documents/resourc esdetail/en/c/1107313/
[15] Genene T. (2006). Farmers' Perceptions of Land Degradation and Determinants of Household Food Security Status at Middle Catchments of Bilate Watershed. A Thesis Prepared to the School of Graduate Studies, Alemaya University.

[16] Gujarati D. N. 2004. Basic Econometrics 4th edition. The McGraw-Hill Companies, New York.

[17] Gulled Abdullahi, (2006). Food insecurity and coping strategies of Agro-pastoral households in Awbare Woreda, Somali Region Ethiopia. An MSc. thesis presented to the School of Graduate studies of Haramaya University.

[18] Haile H. K., Alemu Z. G. Gudhlande G. (2005). Causes of Household Food Insecurity in Koredegaga Peasant Association, Oromiya Zone, Ethiopia. Department of Agricultural Economics, Faculty of Natural and Agricultural Sciences at the University of the Free State, 2005.

[19] Hoddinot J. (ed). 2001. Methods for Rural Development Projects. Food Security in Practice. IFPRI, Washington, D. C.

[20] IFRC (2018). IFRC Situation Report: Regional Food Crisis in Africa - 18 January 2018. Retrieved from http://ifrcgo.org/foodsecurity/img/Africa-Food-CrisisSitRep14.pdf

[21] Kurmuk District Office of Agriculture, (2019). Annual Report. Benishangul Gumuz, Ethiopia.

[22] MoFED (Ministry of Finance and Economic Development), 2008. Dynamics of growth and poverty in Ethiopia. Addis Ababa, Ethiopia.

[23] Nigatu R (2010) Small holder farmers coping strategies to household food insecurity and hunger in southern Ethiopia. Ethiop. J. Environ. Stud. Manag. 4 (1): 39-48.

[24] Sila O. Pellokila R. (2007). Socio-Economic Indicators Affecting food security. University of Philippines at Los Banos.

[25] Tesfaye K. (2005). Household food insecurity in Dodota-Sire districkt, Arsi zone: coping strategies and policy options. M.. Sc. Thesis. School of Graduate Studies of Alemaya University, UNDP, 2014. United Nationts Development Program in Ethiopia, annual report.

[26] WFP, CSA (2014) 'Comprehensive Food Security and Vulnerability Analysis (CFSVA): Executive Summary. Ethiopia.

[27] World Bank (2008). Agriculture for Development. World Development Report 2008, The World Bank. Washington, DC.

[28] Yamane, T. (1967). Statistics, An Introductory Analysis, 2nd Ed., New York.

[29] Yilma M. (2005). Measuring rural household food security status and its determinants in the Benishangul Gumuz region. Master's Thesis, Alemaya University, Alemaya, Ethiopia.

[30] Zerihun N. (2009). Food insecurity, its determinants and rural households coping mechanisms, the case of Mareko woreda, SNNPR, Ethiopia. A MSc thesis presented to School of Graduate Studies, Haramaya University. 